\title{
Mechanical Properties and Structural Analysis of Coatings and Engineered Surfaces
}

\author{
Mattia Merlin *(D) and Annalisa Fortini *( \\ Department of Engineering (DE), University of Ferrara, Via Saragat 1, 44122 Ferrara, Italy \\ * Correspondence: mattia.merlin@unife.it (M.M.); annalisa.fortini@unife.it (A.F.)
}

check for updates

Citation: Merlin, M.; Fortini, A. Mechanical Properties and Structural Analysis of Coatings and Engineered Surfaces. Coatings 2021, 11, 875. https://doi.org/10.3390/coatings 11080875

Received: 13 July 2021

Accepted: 20 July 2021

Published: 22 July 2021

Publisher's Note: MDPI stays neutral with regard to jurisdictional claims in published maps and institutional affiliations.

Copyright: (c) 2021 by the authors. Licensee MDPI, Basel, Switzerland. This article is an open access article distributed under the terms and conditions of the Creative Commons Attribution (CC BY) license (https:// creativecommons.org/licenses/by/ $4.0 /)$.

\section{Introduction and Scope}

The performance improvement in engineering components during operation is a challenging issue and surface engineering methods have been attracting considerable interest in both research and industrial fields. Surface characteristics have a pivotal role in enhancing the life of products since they control the mechanical, electrical, thermal, and electronic properties. Nevertheless, the surface and near-surface properties are crucial in failure mechanisms since the loss of performance and failures mostly begin from the surface.

In this framework, this Special Issue includes original research papers and a review that covers the latest development in methods for enhancing the life and functionality of engineering components by tuning the physical, chemical, mechanical, and metallurgical properties of their surfaces. Attention is focused on processing and characterizing methods capable of supporting industrial applications and products to both tackle surface degradation and improve the performance and reliability of components.

\section{Contributions}

The book collects manuscripts from cutting-edge academic researchers and consists of one review paper regarding the characteristics and mechanical properties of high-velocity oxy-fuel (HVOF) cermet coatings [1] and four research papers focused on the effects of different treatments and coatings on the mechanical and microstructural properties of the investigated material [2-4].

The review by Straffelini and Federici [1] deals with the main characteristics and mechanical properties of HVOF cermet coatings, focusing on the dry sliding behavior of several types of coatings, analyzed at both room and high temperature. Besides, it considers the practical relevance of the proposed topic (i.e., the employment of HVOF coatings for discs in brake applications for the automotive industry, an emerging application that reduces the wear of the braking components, and thus the emission of airborne particulate matter). The review provides a comprehensive synopsis of the recent developments of novel HVOF cermet coatings including Fe-based, Ni-based matrix, and/or submicron-sized carbide and oxide particles.

The effect of plasma electrolytic oxidation (PEO), followed by the deposition of a polymeric layer by the powder coating, on the rotating bending fatigue behavior of the wrought magnesium alloy ZK60A-T5 was studied by Morri et al. [2]. The examined samples, directly extracted from cast-forged wheels to test specimens with the same microstructure of the real component, revealed a reduction in fatigue strength for the PEO-treated specimens. This investigation pointed out that PEO induced a fatigue strength reduction in the range of $14-17 \%$ at $10^{7}$ cycles in comparison with the literature data of untreated alloys. Such a reduction is probably related to the intrinsic defectiveness of the PEO and the residual tensile stresses generated during the treatment.

Another relevant contribution was proposed by Ahmadkhaniha et al. [3]. To enhance the hardness and wear resistance of electrodeposited $\mathrm{Ni}-\mathrm{P}$ and $\mathrm{Ni}-\mathrm{P} / \mathrm{SiC}$ composite coat- 
ings, the authors studied the effect of $\mathrm{SiC}$ particles in combination with different heat treatment conditions on the wear behavior of these coatings. The results demonstrated that $\mathrm{SiC}$ particles significantly influenced the coefficient of friction and the wear rate of the coatings, despite the limited influence in increasing hardness. Besides, after heat treatment, the coefficient of friction trends reported a difference in some relevance between the Ni-P and $\mathrm{Ni}-\mathrm{P} / \mathrm{SiC}$ composite coatings only for the treatment performed at the lowest temperature (i.e., $300{ }^{\circ} \mathrm{C}$ for $2 \mathrm{~h}$ ). This study gives a contribution to the role of $\mathrm{SiC}$ addition and heat treatment on the wear properties of Ni-P coatings, highlighting the optimum condition that minimizes the wear rate.

The paper by Hurtado-Delgado et al. [4] deals with the analysis of ductile irons, with and without austempering heat treatment, and surface hardened by Nd:YAG laser. The aim of the study was to show that the austempered heat treatment before laser hardening is effective in reducing the number of surface microcracks in a wide range of heat inputs. The results indicate that surface hardening via laser is a suitable method for improving wear resistance in critical areas without compromising the core ductility of ductile iron components. The surface ductility is enhanced when the cast iron is austempered before the laser hardening by the reduction of surface microcracks. Austempered ductile irons are less prone to crack formation than ductile irons because they contain less cementite and more martensite and because ausferrite has a higher heat conductivity than pearlite.

Finally, the paper by Fortini et al. [5] deals with hardfacing, a widely used surface coating technique to enhance the corrosive, abrasive, and heat resistance properties of a metal workpiece's surface, especially for heavy-duty applications (e.g., minerals and mining industries, cement plants, paper and pulp industry, thermal power plants, iron and steel industries, etc.). Specifically, the work investigated the microstructural and erosive wear characteristics of a hypereutectic high-chromium cast iron (HCCI) by considering the erosion resistance, resulting from the impact of micro-sized particles, of both the asreceived and heat-treated conditions. The experimental findings showed the efficacy of the adopted destabilization treatment in improving the erosion resistance of the investigated HCCI alloy, which is strongly affected by the matrix/carbides hardness difference.

Author Contributions: Writing—original draft preparation, A.F.; writing—review and editing, M.M. Both authors have read and agreed to the published version of the manuscript.

Funding: This research received no external funding.

Institutional Review Board Statement: Not applicable.

Informed Consent Statement: Not applicable.

Acknowledgments: As Guest Editors, we would like to especially thank Raynor Zhou, Managing Editor, for his valuable support in the publication process. We are grateful to all the contributing authors and reviewers: without their excellent work, it would not have been possible to accomplish this Special Issue.

Conflicts of Interest: The authors declare no conflict of interest.

\section{References}

1. Straffelini, G.; Federici, M. HVOF cermet coatings to improve sliding wear resistance in engineering systems. Coatings 2020, 10, 886. [CrossRef]

2. Morri, A.; Ceschini, L.; Martini, C.; Bernardi, A. Influence of Plasma electrolytic oxidation on fatigue behaviour of ZK60A-T5 magnesium alloy. Coatings 2020, 10, 1180. [CrossRef]

3. Ahmadkhaniha, D.; Lattanzi, L.; Bonora, F.; Fortini, A.; Merlin, M.; Zanella, C. The effect of Co-Deposition of SiC sub-micron particles and heat treatment on wear behaviour of Ni-P coatings. Coatings 2021, 11, 180. [CrossRef]

4. Hurtado-Delgado, E.; Huerta-Larumbe, L.; Miranda-Pérez, A.; Aguirre-Sánchez, Á. Microcracks reduction in laser hardened layers of ductile iron. Coatings 2021, 11,368. [CrossRef]

5. Fortini, A.; Suman, A.; Vulpio, A.; Merlin, M.; Pinelli, M. Microstructural and erosive wear characteristics of a high chromium cast iron. Coatings 2021, 11, 490. [CrossRef] 